\title{
DESENVOLVIMENTO SUSTENTÁVEL DE CIDADES TURÍSTICAS: POSSIBILIDADE OU UTOPIA?
}

\author{
Maria Fernanda Sanchez Maturana ${ }^{1}$ \\ Vitor Augusto Nunes ${ }^{2}$
}

Vagner Sérgio Custódio ${ }^{3}$

\begin{abstract}
RESUMO
O Turismo é uma atividade secular e, nos últimos anos, a ideia de torná-lo sustentável vem sendo discutida, visto que a sociedade está inserida em uma era em que tudo deve ser renovável, rentável e reutilizado. Dessa maneira, o propósito deste artigo é analisar o desenvolvimento econômico do Turismo juntamente com o crescimento dessa prática em cidades turísticas, verificando a veracidade e/ou possibilidade de torná-las sustentáveis, no sentido de incluir a sociedade na atividade turística, visando à minimização dos impactos econômicos, sociais e ambientais. A pesquisa foi realizada a partir de uma revisão bibliográfica com referenciais teóricos e conceitos relacionados a essa temática. Concluiu-se que a sustentabilidade de uma cidade turística só será efetiva quando planejada de forma a inserir suas três dimensões, pois a complexidade do desenvolvimento sustentável não envolve apenas uma diretriz, mas também interesses antagônicos que fazem com que as dimensões não atuem de forma equilibrada e conjunta. Além disso, os incentivos do governo estão voltados principalmente para o âmbito econômico, pois são poucos os municípios que incentivam a consciência ecológica por meio da educação ambiental. Nesse sentido, as cidades turísticas só serão sustentáveis se um novo modelo econômico surgir, agregando todas as dimensões. PALAVRAS-CHAVE: Desenvolvimento. Turismo. Cidade sustentável.
\end{abstract}

\section{SUSTAINABLE DEVELOPMENT OF TOURIST CITIES: POSSIBILITY OR UTOPIA}

\begin{abstract}
Tourism is a secular activity, and, in recent years, the idea of making it sustainable has been discussed, as the society is inserted in an era where everything should be renewable, cost-effective and reused. Thus, the purpose of this article is to analyze the economic development of Tourism along with the growth of this practice in tourist cities, checking the veracity and/or possibility of such cities become sustainable, in order to include society in the tourism industry and minimize economic, social, and environmental impacts. The research was based on a literature review with theoretical frameworks and concepts related to this issue. We concluded that the sustainability of a tourist city will only be effective when planned in order to insert its three dimensions, as the complexity of sustainable development involves not only a guideline, but also antagonistic interests which cause them not to act in a balanced way and jointly. Besides that, government incentives are mainly aimed at economic aspects, because there are few municipalities that encourage environmental awareness through

${ }^{1}$ Discente do curso de turismo, Universidade Estadual Paulista. Ma.fersanchez@hotmail.com ${ }^{2}$ Discente do curso de turismo, Universidade Estadual Paulista. Vitor augustto2011@hotmail.com ${ }^{3}$ Docente do curso de turismo, Universidade Estadual Paulista. Vagner@rosana.unesp.br
\end{abstract}




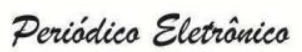

environmental education. In this sense, tourist cities will only be sustainable if a new economic model emerge, joining all dimensions.

KEYWORDS: Development. Tourism. Sustainable city.

\section{DESARROLLO SOSTENIBLE DE LAS CIUDADES TURISTICAS: POSIBILIDAD O UTOPÍA?}

\section{RESUMEN}

El Turismo es una actividad secular y, en los últimos años, se ha discutido la idea de convertirlo en una actividad sostenible, ya que la sociedad se inserta en una era en que todo debe ser renovable, rentable y reutilizado. Por lo tanto, el propósito de este trabajo es analizar el desarrollo económico del Turismo junto con el crecimiento de esta práctica en las ciudades turísticas, comprobando la veracidad y/o la posibilidad de hacerlas sostenibles, en el sentido de incluir la sociedad en la actividad turística, buscando minimizar los impactos económicos, sociales, culturales y ambientales. La investigación se realizó a partir de una revisión de la literatura con los marcos teóricos y conceptos relacionados con este tema. Se concluyó que la sostenibilidad de una ciudad turística solo será efectiva si se planifica con el fin de introducir sus tres dimensiones, ya que la complejidad del desarrollo sostenible no envuelve tan solo una pauta, pero intereses antagónicos que las hacen no actuar de manera equilibrada y en conjunto. Además, los incentivos del gobierno están dirigidos principalmente al ámbito económico, porque existen pocos municipios que fomentan la conciencia ecológica por intermedio de la educación ambiental. En este sentido, las ciudades turísticas solo serán sostenibles si un nuevo modelo económico surge, agregando todas las dimensiones.

PALABRAS-CLAVE: Desarollo. Turismo. Ciudad Sostenible.

\section{INTRODUÇÃO}

O termo desenvolvimento sofreu modificações ao longo do tempo, por ser muitas vezes ambíguo, inconsistente e contraditório. O verbo "desenvolver" foi definido de diferentes maneiras e percebe-se que antes da Idade Moderna o desenvolvimento acontecia de forma lenta havendo um longo processo até chegar à industrialização culminando em um processo de produção massiva e de consumo exacerbado. Mas, esse longo processo de desenvolvimento humano também está diretamente ligado à degradação do meio ambiente (VIEIRA, 2005).

Esse processo se iniciou principalmente com a Primeira Revolução Industrial, que pode ser conceituada como um "conjunto de transformações tecnológicas, econômicas e sociais ocorridas na Europa [...]". (SANDRONI, 2002, p. 528-529). E, essas transformações ocorrem em conjunto com o emprego de máquinas a vapor, fazendo com que houvesse um consumo intensivo do carvão e, consequentemente o aumento da poluição do ar.

Ressalta-se ainda que antes da Revolução Industrial a produção pautava-se na subsistência humana, mas a partir dela a produção começou a ser realizada para satisfazer o mercado capitalista que se iniciava, visando o domínio econômico com 


\section{Periódica Eletrânica

diretrizes voltadas ao lucro. Neste sentido, além da poluição do ar, constatou-se a contaminação do solo, a poluição das águas, a destruição de biomas, dentre outras manifestações de problemáticas ambientais.

A Revolução Industrial impulsionou também o crescimento do espaço urbano, na qual as pessoas se mudavam do campo em virtude das oportunidades de emprego advindas das indústrias, isso aconteceu de forma rápida, inesperada e consequentemente desordenada surgindo então, problemas de infraestrutura, favelização, acúmulo de lixo, foco de doenças, e problemas de saneamento básico em geral (MARCONDES, 2005).

O processo de desenvolvimento da sociedade também foi evidente no pós II Guerra Mundial em meados de 1950, na qual os países menos desenvolvidos buscavam alcançar os mais desenvolvidos e estruturados. A partir da década de 1960, houve uma expansão das preocupações ambientais em todo o mundo. Uma delas, bem marcante, diz respeito aos níveis de emissão de poluentes e o aquecimento global. Essa década ficou marcada pelo surgimento do movimento ambientalista, por consequência do aumento da degradação e pelo crescimento populacional (MARCONDES, 2005).

Já em 1970 tem-se o equacionamento das necessidades básicas com políticas de diminuição da miséria no Brasil, e a continuidade de eventos providos pela preocupação ambiental como a Conferência de Estocolmo.

Entretanto, o desenvolvimento com a ideia de sustentabilidade começou realmente a ser discutido em 1983 por ocasião da Comissão Mundial sobre Meio Ambiente e Desenvolvimento criada pela ONU, presidida pela primeira ministra da Noruega - Gro Harlem Brudtland, onde nesta ocasião propôs que o desenvolvimento econômico fosse atrelado a questão ambiental.

Desde então outros eventos surgiram para discutirem problemas globais e principalmente ambientais como o Rio-92, onde o termo passou a ter mais força e importância, principalmente porque nesta década a preocupação ambiental estava em ápice. Foi o início da tendência do "ecologicamente correto", e do "eco desenvolvimento", com tentativas de direcionar a sociedade para um enquadramento ético, tanto na produção quanto no consumo dos produtos. Neste sentido, Oliveira (2007) diz que 


\section{Periódica Eletrânica

[...] a satisfação das necessidades básicas; solidariedade com as gerações futuras; participação da população evoluída; preservação dos recursos naturais e do meio ambiente; elaboração de um sistema social que garanta emprego, segurança social e respeito a outras culturas; programas de educação. Essa teoria referia-se principalmente às regiões subdesenvolvidas, envolvendo uma critica à sociedade industrial. Foram os debates em torno do eco desenvolvimento que abriram espaço ao conceito de desenvolvimento sustentável. (OLIVEIRA, 2007, p. 19-20).

É importante mencionar ainda que, foi na década de 1990, que o turismo tornou-se uma atividade considerável, sendo importante para as economias dos países, tornando-o uma alternativa viável na minimização de impactos (CASIMIRO, 2002).

O Brasil teve sua urbanização acelerada de forma descontínua, e a quantidade de cidades criadas foram se multiplicando em desacordo com o suporte do espaço que estava sendo apropriado, tornando quase improvável a relação benéfica da permanência humana com a qualidade nos meios urbanos, principalmente se o modelo atual de desenvolvimento não for modificado. É necessária a integração das dimensões sociais, ambientais, econômicas, culturais, mas também a política para que a base econômica se torne inclusiva, e então mais sustentável.

O crescimento populacional urbano aconteceu de forma contínua ao crescimento do turismo. O site eletrônico da Organização Mundial do Turismo aponta que, entre os anos de 1950 e 2000, a movimentação de turistas internacionais cresceu, passando de 25 milhões para 699 milhões. Ou seja, quando o desenvolvimento do turismo é analisado mundialmente, identifica-se facilmente sua relevância econômica. Desta forma, justifica-se a importância que o turismo potencializa positivamente as questões ambientais, já que é um setor crescente e que envolve o deslocamento de pessoas para qualquer lugar do planeta (OMT, 2003).

Mas, para que haja demanda por determinados destinos turísticos, o turismo depende da qualidade não só dos fatores ambientais como (mar, sol, rio, gruta, montanha, selva), mas também os culturais (arquitetura, gastronomia, música, museus, costumes, tradições) e até mesmo os sociais. Entretanto, a atividade só poderá impactar positivamente, quando for explorada de forma organizada, planejada e consciente, podendo então, gerar benefícios para todos os atores envolvidos. 


\section{Periódica Eletrânica

A continuidade ou não do turismo não depende, portanto, apenas do turista, mas sim de todos os agentes e atores envolvidos: "[...] a comunidade precisa ter consciência de que a preservação ambiental - em sua forma mais ampla - é instrumento de prosperidade por meio do lucro com o turismo". (PETROCCHI, 2004, p. 21).

Beni (2001) amplia essa visão afirmando que os bens e serviços formam o produto turístico de uma localidade, mas as "matérias-primas", que realmente atraem o turista são os recursos naturais, culturais e os atrativos da localidade. O turista quer conhecer as crenças, a cultura, a história, os costumes, a gastronomia, entre outros. Logo, para "consumir" o produto turístico, o turista causa, de certa forma, algum impacto.

Casimiro Filho (2002) também relata que a atividade turística poderá promover melhoria nas condições de vida da população residente na região onde se encontram os atrativos turísticos. Isso ocorrerá tendo em vista que, para desenvolver o turismo em uma região, torna-se necessário implantar uma boa infraestrutura básica como: saneamento, transportes, comunicação, estradas e segurança, dentre outros. Assim, essa infraestrutura, uma vez montada, em alguns casos, também poderá ser utilizada pela população onde se encontra os recursos turísticos.

Embora, a listagem de riscos que o envolve também é relevante, como a diminuição na qualidade física do meio ambiente, bem como na qualidade da atividade. Além disso, também poderá desencadear nos núcleos receptores aumento dos preços dos bens e serviços comercializados nesses locais, o que provocará maior impacto se estes forem também consumidos pela população local, bem como valorização excessiva das terras, que serão utilizadas na instalação dos empreendimentos imobiliários. Porém, esses impactos poderão ser minimizados através de um planejamento adequado da atividade turística.

Neste sentido, Silva (1996), relata que:

A turistificação das paisagens ou o processo de mudança de um lugar para
adequá-la à função turística, na maioria das vezes, não consegue
sincronizar o ritmo e o volume da exploração dos recursos com a
capacidade que o meio oferece de suportar esta exploração. (SALVA, 1996
apud CORIOLANO, 2006, p. 36).

O turismo sendo uma atividade econômica como qualquer outra que prioriza o lucro, em alguns casos degrada o meio, mas, de acordo com autores já citados 


\section{Periódica Eletrânica

nesta pesquisa, a atividade também poderá gerar a exclusão social e outros problemas para a comunidade nativa. Sendo assim, esta pesquisa visa analisar a possibilidade do desenvolvimento econômico do Turismo atrelado a um desenvolvimento sustentável de cidades turísticas.

\section{METODOLOGIA}

Para o desenvolvimento de uma pesquisa científica faz-se necessário o uso de uma gama de técnicas que são estipuladas a partir de um determinado método científico. Sendo assim, Marconi e Lakatos (2009) expressam que a metodologia é a explicação rigorosa de atos desenvolvidos por métodos, apresentam ainda que o método é a união de atividades que visam alcançar conhecimentos verídicos facilitando esse processo, e contribuindo nas decisões e nos erros encontrados. A pesquisa presente teve desta forma, um caráter explicativo visando identificar os fatos que determinam ou contribuem para que aconteça o fenômeno estudado, que englobam a complexidade do desenvolvimento sustentável do Turismo.

Sendo assim, utilizou-se a metodologia descritiva com uma revisão bibliográfica a respeito da temática, com autores que tem como linha de estudo o desenvolvimento das cidades, a economia e as questões ambientais.

\section{OS IMPACTOS AMBIENTAIS E A CONTINUIDADE TURÍSTICA}

O consumo do turismo pode impactar de forma direta o ambiente natural, já que ele é o seu principal produto. Esse consumo quando acontece sem a consciência ecológica e sem a noção de minimização de impactos poderá trazer externalidades negativas ao meio evidenciadas em diversos segmentos, seja ele ambiental, social ou cultural. E, como já visto, todos esses elementos contribuem para uma cidade ser ou não considerada sustentável. Desta forma, os custos gerados podem fazer com que o local se torne inapropriado e indesejado pela população e pelos turistas, pois o produto natural é a essência do turismo, e quando ele é degradado a potencialidade turística decai (CASIMIRO, 2002). 


\section{Periódica Eletrânica

Esse ciclo de uso, destruição e dependência com o meio é o que as pessoas ainda demoram a enxergar. Principalmente a visão de que muitos locais só se tornaram turísticos por decorrência das questões sustentáveis, e quando isso acontece à qualidade de vida da população aumenta e os níveis de interesse para conhecer esse destino consequentemente também crescem.

Já quando os custos gerados não são solucionados e o local se torna indesejado, devem-se criar custos defensivos, que seriam formas de minimizar os problemas causados pelo turismo, tentando fomentar a atividade novamente. Para isso, são necessários investimentos em adequações nas vias de acesso, nas acomodações, na infraestrutura geral e especifica do turismo, e principalmente investimentos em programas de educação ambiental tanto para moradores, quanto para turistas, já que as cidades sustentáveis dependem dessa gama de fatores para se constituírem (CASIMIRO, 2002).

Os problemas ambientais podem ser ainda mais evidentes em cidades turísticas, visto que esses destinos recebem um grande fluxo de pessoas e uma grande diversificação de costumes. Quando a relação turista/morador não é equilibrada o local poderá deixar de ser sustentável, prejudicando principalmente os moradores, que terão uma menor qualidade de vida e uma queda na economia em decorrência da diminuição turística.

Neste sentido, Leff (2001, p.15) diz que: "A crise ambiental veio questionar a racionalidade e os paradigmas teóricos que impulsionaram e legitimaram o crescimento econômico, negando a natureza". A partir dessa lógica surge a necessidade de questionar a produção humana e o modelo de desenvolvimento vigente, buscando alternativas vinculadas ao planejamento e gestão, pois os problemas ambientais fez com que o modelo econômico dominante atual fosse considerado um risco, impulsionando desta forma discussões a respeito do turismo, por ser uma atividade visivelmente econômica e uma possibilidade para a minimização de impactos.

Mas, como deve ser criado um novo modelo econômico para que o turismo e suas cidades em si sejam sustentáveis? Seria possível criar um modelo de desenvolvimento aliando diferentes interesses principalmente os econômicos com os ambientais? 
4 DIRETRIZES PARA O DESENVOLVIMENTO DO TURISMO SUSTENTÁVEL

A OMT (Organização Mundial do Turismo) aborda o desenvolvimento sustentável do turismo:

[...] atende as necessidades dos turistas hoje e das regiões receptoras, ao mesmo tempo em que protege e amplia as oportunidades para o futuro. É visto como um condutor para o gerenciamento de todos os recursos, de tal forma que as necessidades econômicas, sociais e estéticas passam ser satisfeitas sem desprezar a manutenção da integridade cultural, dos processos ecológicos e essenciais, da diversidade biológica e dos sistemas que garantem a vida. (OMT, 2003, p. 24).

Para que isso realmente se constitua elementos precisariam se relacionar de forma equilibrada sendo: economicamente viável, socialmente justo e ecologicamente correto (OMT, 2003).

A busca pelo desenvolvimento sustentável seria pautada na qualidade das populações e turistas a partir principalmente do equilíbrio entre o planejamento urbano com o ambiental, relação esta considerada indissociável, por envolver a relação do ambiente natural com o ambiente construído no qual o turismo se insere.

Para uma cidade ser sustentável atrelando todos os âmbitos já citados, ela precisa além da relação turismo/morador, criar ou ampliar algumas diretrizes, além de que o termo envolve mudanças de estilos de vida, de costumes, de ações, conhecimento, avanço tecnológico, evolução.

Desta forma, quando se relatam especificamente sobre as cidades é válido dizer que elas foram construídas por pessoas e para as pessoas, e desta forma, só mudam quando as pessoas também mudam. Mas, para isso é necessário à equidade e a cooperação.

Destaca-se ainda que a utilização racional e o lucro é o grande desafio para a sustentabilidade, e principalmente quando envolve o turismo no Brasil, onde o produto turístico é voltado quase sempre ao patrimônio natural. Neste sentido, evidencia-se que o termo desenvolvimento pode ser atrelado a inúmeros paradigmas como já exemplificado, e pensando então nas cidades sustentáveis, deve-se pensar também em um turismo sustentável, pois uma cidade turística só será sustentável, se toda a rede do turismo também for.

Entretanto, de acordo com pesquisadores sobre o termo, Carla Canepa (2007), José Eli da Veiga (2005) e Henri Ascelard (1999), o desenvolvimento sustentável ainda não possui uma definição que seja considerada correta por ter 


\section{Periódica Eletrânica

diversas concepções e por ser associado a diversos outros paradigmas e possibilidades.

O termo muitas vezes é confundido com outros conceitos são similares, porém que possuem outras essências, como relata Castro apud Adas (1998, p.90): "Crescer é uma coisa; desenvolver, outra. Crescer é em linhas gerais fácil. Desenvolver equilibradamente, difícil". Desenvolvimento se diferencia do termo crescimento principalmente pelo crescimento numérico, por exemplo, o aumento do PIB brasileiro não significa que a população toda está sendo beneficiada, neste caso, crescer não significa desenvolver. Isso acontece porque o desenvolvimento só se consolida quando há uma distribuição de renda igualitária. Desta forma, crescimento não trás qualidade de vida a população.

Neste sentido, Nascimento (2008) defende a concepção de que o crescimento econômico por si só não reduz a pobreza, em razão de não haver uma distribuição igualitária da renda auferida no sistema econômico, ou seja, o modelo econômico com base em dados quantitativos.

Mas, um elemento comum às definições de diferentes autores seria a ideia de mudança, processo, e movimento, além de que, é inegável que o desenvolvimento pode acontecer independente de ter ou não uma conceituação em comum.

Desta forma, deve-se pensar com uma visão global do turismo, pois os elementos que compõem o meio ambiente são interdependentes e interligados, em formato de rede, na qual, quando uma ação é realizada localmente ela poderá ser repercutida em um outro local do Planeta, de forma positiva ou não. Desta forma, não ser sustentável em um lugar e ser sustentável em outro pode fazer com que essa relação seja pouco benéfica.

Neste sentido, Capra (1982, p.14) reforça a ideia:] “[...] vivemos num mundo globalmente interligado, no qual os fenômenos biológicos, psicológicos, sociais e ambientais são todos interdependentes". Complementando a discussão Lima (2005, p. 26) diz que há uma: "[...] ocorrência simultânea e interdependente da degradação humana, social e ambiental". 


\section{A DESVALORIZAÇÃO NATURAL E O CONSUMISMO}

O homem deve se ver como parte integrante do meio ambiente, pois desde os primórdios da humanidade as pessoas dependem da natureza para sobreviverem, e este processo de desenvolvimento da humanidade de alguma forma sempre impacta o meio. Entretanto, o homem enxerga o mundo de forma diferente, tendo uma concepção nula de tudo o que cerca (BACHELET, 1995).

A exploração dos recursos naturais e a consequente degradação ambiental esta cada vez se agravando mais, principalmente pelo processo de exploração, transformação e produção de produtos na era capitalista e o esquecimento de uma geração futura que também dependerá nos recursos naturais pra virem a existir.

Sendo assim, o desenvolvimento deveria englobar diversos elementos que influenciam a relação do homem e o meio, como: ambientais, políticos, administrativos, sociais, econômicos, culturais, dentre outros fatores importantes. Entretanto, pelo Turismo representar altos índices econômicos dentro do PIB brasileiro, o fator econômico muitas vezes é o único considerado, mas essa evidência não faz com que o local onde o Turismo está inserido realmente se desenvolva, como já discutido (CAPRA, 1982).

Sendo assim, pode-se ressaltar a importância dos fatores econômicos no mundo capitalista atual, no qual as empresas pensam apenas na expansão e na acumulação de capital, Ao analisar o intuito de uma empresa, seria indiscutível e inadequado dizer que o fator econômico não deve ser pensado de forma prioritária, pois por ser uma empresa, ela depende principalmente deste fator para se consolidar.

Mas, isto não significa que a empresa não pode atrelar os outros elementos em sua forma de produção. Um problema evidente é a dificuldade em que as empresas possuem na concepção de que o desenvolvimento sustentável traria autobenefícios a elas, e que os investimentos trariam vantagens a curto prazo (BACHELET, 1995).

A partir disso, complementa-se que a sociedade capitalista atual está inserida em uma concepção na qual o "ter é mais importante do que o ser", mas essa expansão e acumulação de bens e capital não fazem com que a sociedade viva com uma maior qualidade de vida. Esta explanação esta pautada nas empresas que por 


\section{Periódica Eletrânica

evidenciarem os aspectos econômicos e não trabalham na qualidade e no significado que o produto final terá para o consumidor, tornando o ciclo de vida dos produtos menores de forma a torna-los descartáveis (CANEPA, 2007).

Isso pode ser exemplificado pela obsolescência programada do mundo capitalista atual, na qual os produtos são produzidos com prazo de vida préestabelecidos, fazendo com que eles sejam trocados por outros mais rapidamente. Estes fatores são frequentes porque o mercado precisa estar em constante movimento, onde o produtor passa a produzir cada vez mais, procurando atender uma demanda cada vez maior, de acordo com as suas necessidades e exigências de possuir um determinado serviço, ou talvez pelo o produto the oferecer certo status.

Mas, o que isso poderia impactar nas cidades? A discussão presente possui ligação direta nas cidades, principalmente nas turísticas que possuem maior dificuldade em se tornarem sustentáveis. A obsolescência e a prioridade econômica da sociedade atual são os principais causadores dos problemas ambientais. A sociedade impõem as pessoas a sempre comparem mais, independente da necessidade que isto terá para elas, e isto faz com que a acumulação de capital se transforme na acumulação de resíduos sólidos, grande causadora de impactos.

Além de que, até mesmo em países menos desenvolvidos, as populações mais carentes buscam possuir novas tecnologias, e muitas vezes isso impede a sociedade de se desenvolver, pois com o consumo desnecessário, a qualidade de vida pode se estagnar, visto que, neste processo consumista, a preocupação ambiental não é frequente (ASCELARD, 1999).

Mas, esse consumismo exacerbado e desnecessário pode ser inserido no turismo? De que forma isso ocorre nas cidades? O turismo faz parte deste mundo capitalista pautado na ostentação social, no qual muitas pessoas consomem o espaço de forma inadequada, não pensam em seu lazer que the trará uma melhor qualidade de vida, e acabam viajando para determinados locais simplesmente por quererem se inserir no mundo globalizado onde todos gostam e consomem as mesmas coisas.

Entretanto, a indústria do turismo envolve muitos outros fatores que devem ser englobados no desenvolvimento sustentável. Um primeiro ponto a se analisar é que o desenvolvimento do turismo vai acontecer independente dos seus paradigmas 


\section{Periódica Eletranica

e concepções, um segundo ponto é que o fator econômico é um dos elementos primordiais ao turismo, um terceiro ponto e então fundamental é que as singularidades dos locais são essenciais para que o turismo continue se desenvolvimento diferentemente do que a globalização impõe e o último e tão fundamental quanto os outros pontos é que o turismo diferentemente dos outros produtos tem o ambiente natural como essência, sendo dependente dele para continuar a se constituir (VIEIRA, 2005).

$\mathrm{E}$, pelo Turismo se concretizar principalmente por produtos advindos do meio ambiente, o foco desta análise é enfatizado, por verificar o desenvolvimento do turismo com o paradigma sustentável, pois a atividade esta relacionada e depende diretamente da natureza para se constituir. Entretanto, há um grande contraste neste processo, pois com o Turismo o ambiente pode ser impactado prejudicando a própria atividade, mas se bem planejado ele poderá ser uma forma alternativa de proteger o ambiente natural (VIEIRA, 2005).

O Brasil é reconhecido e procurado por suas belezas naturais e pela sua rica biodiversidade, e ainda hoje todo esse potencial não é aproveitado totalmente pelo turismo. Mas, vale a reflexão. Será mesmo que o país deveria usar todo a sua riqueza? Será mesmo que a atividade turística poderia contribuir para a preservação do local? Neste sentido, vale destacar a essência que o turismo possui em ser uma alternativa e uma ferramenta para evitar degradações.

Entretanto, o que deve ser analisado, é se as cidades e as pessoas estão realmente preparadas para exercerem a atividade de forma positiva e não de forma impactante. Outra reflexão seria acerca dos termos preservação e conservação. Neste caso, preservar seria utilizar o território natural de forma consciente, evitando impactos (CANEPA, 2007).

Mas, caso o turista esteja prejudicando e impactando as cidades, a concepção ideal seria a conservação, na qual tornaria as áreas verdes das cidades intocáveis, criando mais áreas de preservações, como os parques municipais, estaduais e nacionais, delimitando a atividade turística. Ou seja, o turismo deve ser sustentável para ser algo positivo nas cidades.

Neste sentido, é válido relatar que a globalização evidencia cada vez mais o Turismo de massa, fazendo com que as pessoas viagem em grupos, e segundo Badaró (2003), o início da década de 1970, em decorrência da elevação da 


\section{Periódica Eletrânica

demanda por turismo, os turistas passaram a serem considerados como devoradores de paisagens e do meio ambiente.

Esta concepção vai de encontro aos preceitos do turismo, que deveria ser visto como uma alternativa de preservação ambiental. Desta forma, a ideia de massificação turística não deve ser vista de maneira generalizada como um ponto negativo, pois as classes menos favorecidas que buscam viajar para lugares comuns e em grande quantidade de pessoas não deve deixar de ocorrer, mas deve acontecer de forma mais cuidadosa, uma vez que é de direito de todos terem acesso à cultura, ao conhecimento, de ir e vir, ao lazer, entre outros.

O turismo de massa precisa envolver as premissas ambientais em busca do menor impacto possível, e esta relação pode ser favorecida diretamente pela educação ambiental. Isto seria um passo positivo para que a massificação não atrapalhe uma cidade de ser sustentavelmente desenvolvida.

Já o turismo alternativo, seria uma categoria que se contrapõe ao turismo de massa. Este tipo de segmento acontece de forma mais controlada, ou seja, o turista viaja já com a concepção e com a consciência de minimização de impactos. 0 turismo alternativo está evoluindo e está associado ao turismo ecológico, turismo de selva, ecoturismo, dentre outros. Esta preocupação está interligada principalmente pelas atividades desses segmentos acontecerem diretamente nos espaços naturais como a maioria dos segmentos turísticos que acontecem no Brasil (BADARÓ, 2003).

O turista pode viajar e praticar o turismo da forma que puder e desejar, sozinho, ou em grupo, isso está relacionado com as razões, objetivos e interesses para o seu deslocamento, mas independe da situação, ele deve ser consciente e evitar maiores impactos no espaço que for praticar o turismo, pois para que a cidade turística seja sustentável o turista deve estar engajado nas suas concepções.

\section{CONSIDERAÇÕES FINAIS}

A sustentabilidade de uma cidade, principalmente quando ela insere o turismo deve ser planejada de forma a englobar as dimensões já abordadas, pois a complexidade do desenvolvimento sustentável não envolve apenas enfoques ambientais ou econômicos. 


\section{Periódica Eletrânica

São elas: a sustentabilidade social que está ligada diretamente com a melhoria na distribuição de renda e a redução das diferenças sociais, neste sentido, ressalta-se a diferença de crescimento e desenvolvimento; a sustentabilidade econômica que tem vínculo direto com o fluxo constante dos investimentos públicos e privados, levando em conta a administração correta dos recursos naturais; a sustentabilidade ecológica que procura o uso efetivo dos recursos existentes nos vários ecossistemas, mas prioriza a mínima deterioração ambiental; a sustentabilidade espacial/geográfica que está ligada a uma espacialização cidade/campo mais equilibrada; e por fim, a sustentabilidade cultural que busca a prática de mudanças em conformidade com a continuidade da cultura vigente (ACSELRAD, 1999).

Mas, os interesses antagônicos acabam fazendo com que essas dimensões não atuem de forma equilibrada e conjunta, e a complexidade existente nas estratégias de desenvolvimento dificulta 0 estabelecimento de critérios de sustentabilidade na sociedade moderna. Desta forma, muitas vezes uma cidade não é sustentável porque os atores que a envolvem não os são. Ou seja, para a sustentabilidade da cidade e do turismo, a população e os turistas também precisam ser sustentáveis para agirem de forma sustentável, visando o uso do espaço de forma menos impactante.

$E$, é neste sentido que o turismo também deve ser planejado para que seja implantado em regiões adequadas, pois não basta o local ter potencial, é necessário que ele tenha estruturas de apoio à atividade, além de que a população precisa querer receber o turista em sua comunidade. E, só assim o turismo poderá ser uma alternativa econômica de desenvolvimento local.

O que se pode concluir é que os incentivos do governo são voltados principalmente no âmbito econômico, e são poucos os municípios que incentivam a consciência pela educação ambiental, por exemplo. Além de que, as áreas de conservação muitas vezes são criadas sem planejamento e em áreas muitas vezes inadequadas, simplesmente pelo lucro que irão gerar. $\mathrm{E}$, além do mais, os benefícios advindos do setor turístico poucas vezes são revertidos para o desenvolvimento sustentável do mesmo. 


\section{Periódica Eletrânica

Neste sentido, as cidades turísticas só serão sustentáveis se o novo modelo econômico abordado surgir a partir de um incentivo governamental, para que assim as dimensões se agreguem e tornem as cidades mais sustentáveis.

\section{REFERÊNCIAS}

ACSELRAD, H.; LEROY, J. P. Novas premissas da sustentabilidade democrática. Revista Brasileira de Estudos Urbanos e Regionais, 1, 1999.

ADAS, M. Panorama geográfico do Brasil: Contradições, impasses e desafios. 3. ed. São Paulo: Moderna,1998.

BACHELET, M. Ingerência Ecológica: Direito Ambiental em questão. Lisboa: Instituto Piaget, 1995.

BADARÓ, R.A.L. Turismo e direito: convergências. São Paulo: Editora Senac São Paulo, 2004.

BECK, Ulrich. Democracia y sus enemigos: textos escogidos. Barcelona: Paidós, 2000.

BENI, M.C. Análise estrutural do turismo. São Paulo: SENAC, 2001.

CANEPA, C. Cidades Sustentáveis: o município como lócus da sustentabilidade. São Paulo: Editora RCS, 2007.

CAPRA, F. O ponto de mutação. A ciência, a sociedade e a cultura emergente. São Paulo, Cultrix, 1982.

CASIMIRO. F.F. Contribuição do turismo à economia brasileira. Ed. Piracicaba, 2002.

LEFF, E. Saber Ambiental. Petrópolis- RJ: Vozes, 2001.

LIMA, M. J. O. Serviço Social na empresa: um estudo do trabalho do assistente social na gestão de Recursos Humanos. 2002. 127 f. Dissertação (Mestrado em Serviço Social), Faculdade de História, Direito e Serviço Social, Universidade Estadual Paulista, Franca, 2005.

MARCONDES, D. A crise de paradigmas e o surgimento da modernidade. In: BRANDÃO, Zaia (org.). A crise dos paradigmas e a educação. 9 ed. São Paulo: Cortez, 2005.

MARCONI, M. A.; LAKATOS, E. M. Fundamentos da metodologia científica. São Paulo: Atlas, 2009.

NASCIMENTO, L.F.F; LEMOS, A.D.C.L; MELLO, M.C.A. Gestão Socioambiental estratégica. São Paulo: Bookman, 2008.

OLIVEIRA, D.P.R. Planejamento Estratégico: conceitos, metodologia e práticas. 23. ed. São Paulo: Atlas, 2007.

ORGANIZAÇÃO MUNDIAL DO TURISMO (OMT). Guia de desenvolvimento do turismo sustentável. Porto Alegre: Ed. Bookman Companhia, 2003.

PETROCCHI, M. Turismo, planejamento e gestão. São Paulo: Peardon Education, 2004.

SANDRONI, P. Novíssimo dicionário de economia. 5. ed. São Paulo: Best Seller, 2000. 300 p.

SILVA, T.T Identidades terminais: as transformações na política da pedagogia e na pedagogia da política. Petrópolis: Vozes, 1996. 